In other words, China's eugenic ambitions are no more likely to be attainable now than they would have been at the beginning of this century, when so much less was known. In the end, like other countries, China will have to learn to live with the social and economic burden of disability apparently unavoidable in a diverse community. In the meantime, it is earnestly to be hoped that misplaced ambition does not tempt the Chinese government to impose ineffectual constraints on its vast population, still reeling from the draconian aspects of the "One couple, one child" regime.

\section{Too old at 59?}

The birth of artificially conceived twins to a woman of 59 has provoked a characteristically British fuss.

FOR some years there has been a sprinkling of births to postmenopausal women, all born of the recognition that the chief characteristic of the human menopause is the disappearance of the hormones that make conception and pregnancy possible. The first cases were publicly reported from California three years ago, but last week the British newspapers were telling, with customary sanctimonious humbug, how a British woman had given birth to twins at the ripe old age of 59 .

Proper anxieties about the continuing war in Bosnia, the political succession in Russia and the continuing high level of unemployment in Europe notwithstanding, several politicians have discerned further evidence of social disintegration in what would traditionally have been regarded as a happy event. The general opinion is that "something will have to be done". Mrs Virginia Bottomley, Secretary of State for Health, on this occasion more circumspect than usual, followed the remark that "women do not have a right to have children" with a promise that she would bring up the ethical issues raised by the artificial conception with her counterparts in the other 11 governments of the European Union (the prenatal procedures had been carried out in Rome).

The difficulty is that no new ethical issues are raised by the application of in vitro fertilization (IVF) to older women. As now practised, IVF is controlled by physicians, whose first responsibility must be to their patients and includes the duty to counsel them about the risks involved in giving birth at an unusually great age. Plainly there are several: not merely the increased risks of childbirth itself, but the risk that it will not be possible to provide a child with the personal care it needs during its formative years. The same questions arise with women seeking more common IVF treatment, for they are at the older end of the usual spectrum of childbearing age. At the very least they have usually been seeking pregnancy by natural means for some years before going to an infertility clinic.

So there is no sharp division between the ages of the women seeking help nor is the treatment offered sharply different. Bottomley is thus likely to be treated to indulgent smiles when she brings up the matter with her less sheltered European colleagues, which is just as well.

\section{What priority for TB?}

Western governments must recognize the need to combat TB in developing nations - if only in self-defence.

THE World Health Organization (WHO) recently published a report on tuberculosis with a dramatic title that neatly sums up the reaction of governments everywhere to what is now the most prevalent fatal infection: TB: A Global Emergency -Low Priority. And that is exactly the spirit in which the US Agency for International Development (AID) recently turned down a request from WHO for $\$ 3$ million to fight TB in developing countries. (As part of a United Nations campaign, WHO is trying to raise a total of $\$ 9$ million.) Yet tuberculosis is likely to kill 30 million people before the turn of the century. The number could be higher if drug-resistant strains of the TB mycobacterium continue to proliferate.

But US AID, a $\$ 6.5$ billion agency, could not come up with the $\$ 3$ million: Ann Van Dusen, an AID officer, said: "In the budget environment that we're looking at, it is a lot of money". That is either just plain nonsense ( $\$ 3$ million is not a lot of money for the US government) or else represents priorities distorted beyond belief. In a news report, Van Dusen defended the agency's decision, saying that AID is already spending a lot of money on AIDS, for instance.

And an AID officer correctly pointed out that the agency has money for TB in many of its local health programmes. But no total dollar sum is available, which in itself is a sign of TB's low visibility within AID.

Does AID not realize the lethal connection between tuberculosis and AIDS? Not only in developing countries but also in Western nations, TB is flourishing because AIDS patients whose immune systems are severely compromised are ideal hosts. It is regrettable but true that AIDS patients provide the bacillus with a ideal reservoir in which to mutate into drug-resistant forms. The best of all strategies, therefore, would be to tie TB and AIDS fundings together whenever possible. After all, to prevent the spread of drugresistant TB in developing nations is to protect the populations of more developed nations as well.

Unlike AIDS, tuberculosis is not difficult to catch. A readily transmissible disease that has even been passed on to passengers on airplanes, it is urgent to take its resurgence seriously. According to WHO data, US AID is not the only national agency to resist the call for funding in the fight against TB. European nations too have been reluctant to contribute.

This sets the stage for a global tragedy. Unlike AIDS, cancer, neurodegenerative diseases and other maladies that await new scientific understanding before they can be cured, the treatment of TB (particularly non-resistant strains) is well-understood and in developing nations is relatively inexpensive - as little as $\$ 30$ a patient.

If ever there were a challenge worth taking on, the fight against the worldwide spread of tuberculosis should top the list. World governments should do all they can to negate WHO's statement that TB is being rated "low priority". 